\title{
MECHANICAL PERFORMANCE OF LAP JOINTS OF FLAT ROOF WATERPROOFING MEMBRANES SUBJECTED TO ARTIFICIAL WEATHERING
}

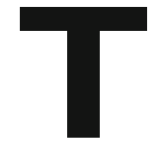

he flat roof of a building, here understood as the whole of every construction element from the ceiling to the surface exposed to climatic agents, is made of a set of horizontal or quasi-horizontal layers that satisfy its functional demands.

The waterproofing layer is fundamental in most flat roofs and, of the various options, single-layer systems made of prefabricated membranes and mechanically fastened are one of the most frequently used in Portugal. This solution is also used to repair roofs' waterproofing systems without having to remove the existing layers, thus reducing the cost.

However, it is well known that the performance of these systems is strongly influenced by the efficiency of the membrane fastenings, which is directly related to the membranes' nature and the design and execution of the lap joints. Many of the anomalies that occur are related to the deficient execution of the membranes' lap joints ${ }^{1-3}$ and the consequent faulty performance when subjected to average environmental agents. Studies undertaken in Portugal on the behavior of lap joints in membranes made or commercialized in this country 4,5 have corroborated other studies in this area and shown that certain membranes perform worse than others when used in single-layer systems. Three different solutions were tested: amyloid precursor protein (APP)and Styrene-Butadiene-Styrene (SBS)-modified bituminous membranes and polyvinyl chloride (PVC) membranes. Of the bituminous membranes, the SBS ones produced and commercialized in Portugal presented, as expected, much more satisfactory mechanical characteristics than the APP ones, thus justifying a more thorough study of their suitability for use in mechanically fastened single-layer systems.

This paper aims to show how artificial weathering of the lap joints of SBS-modified bituminous membranes is reflected in their mechanical performance when subjected to peeling forces (Fig. 1a) or shear forces (Fig. 1b). These forces aim to reproduce the effects of the action of wind on these membranes. The effect on waterproofing systems is dealt with in detail in the corresponding European Organisation for Technical Approvals (EOTA) Guideline, ${ }^{6}$ where the tests described below are given due emphasis. The research work reported here involved shear and peel resistance tests carried out on lap joints of SBS-modified bituminous membranes, 50and $100-\mathrm{mm}$ wide, made both with welding gas torch and hot air and artificially weathered by water and heat. It must be noted that the shear and peel resistance tests are also part of the harmonized European standards on the bituminous and

M. Gonçalves is an Auxiliary Professor in MSc Construction (IST), Instituto Superior de Engenharia de Lisboa (ISEL), Lisbon, Portugal. J.G. Lopes is a Senior Research Officer, National Laboratory of Civil Engineering (LNEC), Lisbon, Portugal. J. de Brito (jb@civil.ist.utl.pt) is a Full Professor, Instituto Superior Técnico (IST), Technical University of Lisbon, Lisbon, Portugal. synthetic membranes' characteristics ${ }^{7}$ that support their $\mathrm{CE}$ marking.

However, European standardization does not take into account demands on the performance of lap joints, both for new membranes and those weathered by the main environmental agents. To acquire data on this aspect, the only resort is documentation from a nonofficial European organization (UEAtc), some of which is relatively old..$^{8,9}$ Therefore, this paper also aims at contributing to provide a vast set of results of peeling and shear tests of lap joints. Out of the list of tests mentioned in the relevant European standardization, these are among those with the highest results scatter, leading to wider discussion on their adequacy to reproduce the on-site performance of these joints. Publishing these results may also contribute to the definition of acceptance/rejection criteria (requisites) for a given roofs waterproofing system whenever there are actions that may lead to peeling or shear stresses in the joints.

\section{EXPERIMENTAL WORK}

\section{Materials and Test Samples}

SBS-modified bituminous membranes produced and commercialized in Portugal were used, reinforced with $150 \mathrm{~g} / \mathrm{m}^{2}$ nonwoven polyester felt.

The main identification characteristics of the membranes used are presented in Table 1.

Membranes were cut into samples of around $0.8 \times 0.5 \mathrm{~m}$ so that they could be transported unrolled. In order to guarantee the constant lapping width of the samples, an aluminum selfadhesive strip was placed on the corresponding borders. Two processes were used to execute the joints: A propane gas torch and an automatic control hot air gun. In both cases, manual equipments operated by expert experienced staff were used and no measurements were performed of the distance and incidence angle of the flame or air flux, or of the speed of evolution of the equipment. Only the hot air gun, with a nozzle $50-\mathrm{mm}$ wide, allowed the control of the speed of the air coming out $(8.5 \mathrm{~m} / \mathrm{s})$. Because there was no equipment to quantify these parameters, it was empirically guaranteed that the distance from the membrane, the incidence angle, and the speed of the evolution of the torch and gun were kept as constant as possible during the execution of all the joints. Furthermore, proper care was guaranteed during execution, that is cleaning the surfaces to be bonded, ensuring the chemical, hygrometric, and mechanical compatibility of the membrane and the substrate surface.

The test samples thus produced were cut transversely to the lap joints, using a hydraulic guillotine, in 15 strips $50-\mathrm{mm}$ 


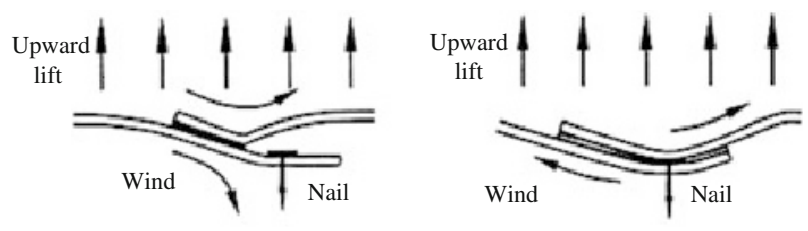

Fig. I: Peeling forces (a) and shear forces (b) caused by wind on lap joints ${ }^{2}$

wide. Each strip was later cut using a manual guillotine, providing a single specimen.

Figures 2 and 3 show the test samples from which the specimens were taken for the shear and peel resistance tests.

All the materials, from membranes to specimens, were stored in an air-conditioned room at between 22 and $25^{\circ} \mathrm{C}$, with relative humidity between 50 and $70 \%$.

As shown in Table 2, 360 test specimens were cut from 24 test samples. Of these 180 were prepared for the shear resistance test (designated with the letter $\mathrm{T}$ ) and the other 180 were prepared for the peel resistance test (designated by the letter P).
According to the UEATc guide, ${ }^{10}$ weathering lap joints by heat consists of keeping the specimens for 28 days in an oven artificially maintained at $80^{\circ} \mathrm{C}$. For water weathering, according to same guide, the specimens must be kept for at least 7 days under water at $60^{\circ} \mathrm{C}$; however, in this research, the weathering period was increased to 3 months both inside the oven and under the water, thus creating more demanding situations.

\section{Test Procedures}

The shear resistance tests were conducted according to EN 12317-1. ${ }^{11}$ The test consists of applying a tensile load to a specimen (Fig. 4) at constant speed until the specimen breaks or its elements separate.

The peel resistance tests were conducted according to EN 12316-1. ${ }^{12}$ The test consists in pulling apart a specimen (Fig. 5) at constant speed until total separation of the specimen elements by peeling.

A stress-measuring device (Fig. 6) was used for the shear and peel resistance tests. It was equipped with gages to continuously record the force and corresponding strain and with devices to keep the displacement speed constant over time and to maintain or increase the pressure of the grips on the specimen (depending on the force increment applied to it).

\section{Table I -Identification characteristics of the SBS-modified bituminous membranes (values declared by the manufacturers)}

\begin{tabular}{lccc}
\hline NOMINAL THICKNESS $(\mathrm{mm})$ & MASS PER UNIT AREA $\left(\mathrm{kg} / \mathrm{m}^{2}\right)$ & MAXIMUM FORCE IN TENSION (N/5 cm) & RUPTURE STRAIN* (\%) \\
\hline 4 & 4.0 & $500(\mathrm{~L})$ & 30 (L) \\
& & $300(\mathrm{~T})$ & 30 (T)
\end{tabular}

*(L) - longitudinal direction; (T) 一 transversal direction.

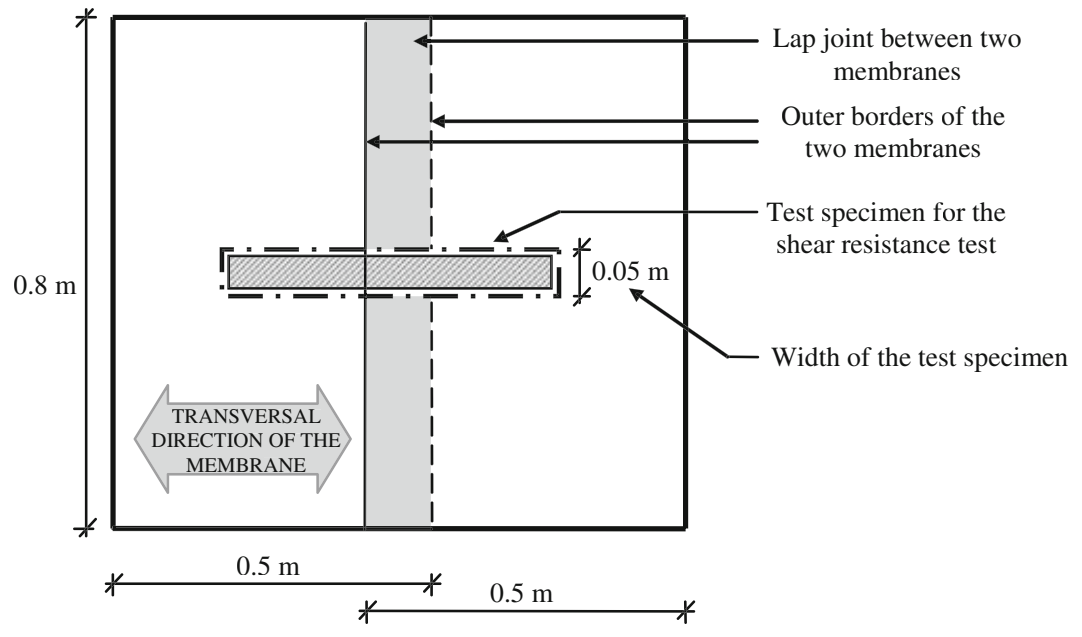

Fig. 2: Test sample and test specimen for the shear resistance test (see also Fig. 4$)^{5}$ 


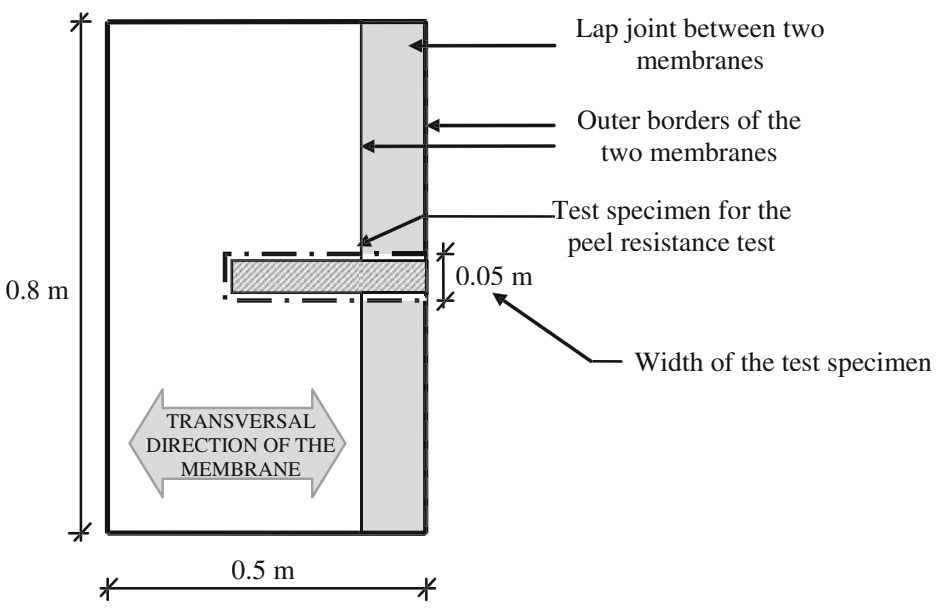

Fig. 3: Test sample and test specimen for the peel resistance test (see also Fig. 5) ${ }^{5}$

Table 2-Distribution of the test specimens

TOTAL: 360

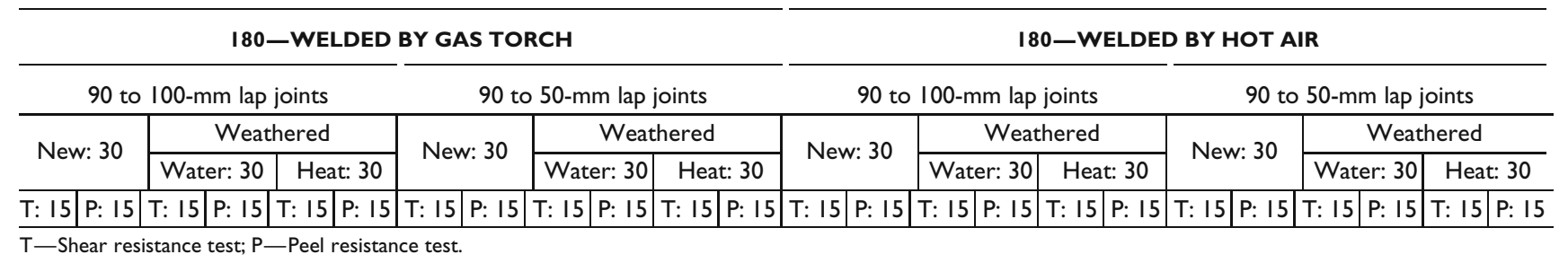

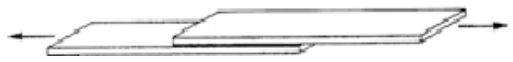

Fig. 4: Specimen for the shear resistance test ${ }^{5}$

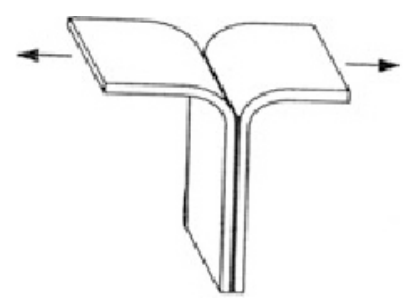

Fig. 5: Specimen for the peel resistance test ${ }^{5}$

The following procedures applied all the tests:

- The initial position of the grips was marked on each specimen in order to identify any slipping;

- The grips were positioned on each specimen so that its longitudinal axis and the center of the grips were correctly aligned;

- No preload was applied;

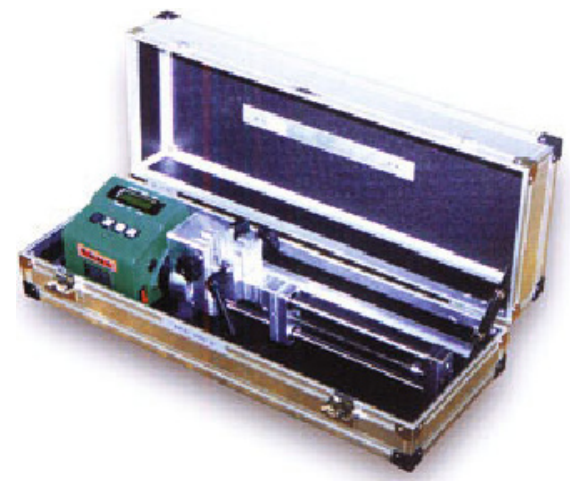

Fig. 6: Stress-measuring device (Examo 600 F - Leister Process Technologies, Kaegiswil, Switzerland) used for the shear and peel resistance tests

- The tests were performed carried out at a temperature of $23 \pm 2{ }^{\circ} \mathrm{C}$ and a constant displacement speed of $100 \pm$ $10 \mathrm{~mm} / \mathrm{min}$, as stated in the standards mentioned above.

For the shear resistance tests, the initial distance between the grips was $200 \pm 5 \mathrm{~mm}$ and for the peel resistance tests distance was $100 \pm 5 \mathrm{~mm}$. 
Table 3-Results of the shear resistance tests (adapted from Gonçalves ${ }^{4}$ )

\begin{tabular}{|c|c|c|c|c|c|c|c|c|c|c|c|c|c|}
\hline \multicolumn{2}{|c|}{ WEATHERING STATE } & \multicolumn{4}{|c|}{ NEW } & \multicolumn{4}{|c|}{ WATER WEATHERED } & \multicolumn{4}{|c|}{ HEAT WEATHERED } \\
\hline \multirow[t]{2}{*}{ LAP JOINTS } & \multirow{2}{*}{$\begin{array}{c}\text { WELDING PROCESS } \\
\text { WIDTH }(\mathrm{mm})\end{array}$} & \multicolumn{2}{|c|}{ GAS TORCH } & \multicolumn{2}{|c|}{$\overline{\text { HOT AIR }}$} & \multicolumn{2}{|c|}{ GAS TORCH } & \multicolumn{2}{|c|}{ HOT AIR } & \multicolumn{2}{|c|}{ GAS TORCH } & \multicolumn{2}{|c|}{ HOT AIR } \\
\hline & & 100 & 50 & 100 & 50 & 100 & 50 & 100 & 50 & 100 & 50 & 100 & 50 \\
\hline $\operatorname{MRC}(\mathrm{N})$ & & 452 & 450 & 447 & 456 & 475 & 459 & 470 & 470 & 501 & 523 & 486 & 499 \\
\hline$\sigma(\mathrm{N})$ & & 30 & 26 & 23 & 31 & 26 & 31 & 30 & 30 & 35 & 26 & 66 & 48 \\
\hline \multirow{2}{*}{ Strain at maximum force $(\%)$} & Minimum value & 34 & 27 & 33 & 44 & 42 & 30 & 34 & 42 & 10 & 19 & 5 & 14 \\
\hline & Maximum value & 46 & 56 & 46 & 59 & 50 & 49 & 46 & 54 & 28 & 37 & 30 & 40 \\
\hline \multirow{4}{*}{$\begin{array}{l}\text { Mode of failure* (number of } \\
\text { specimens tested) }\end{array}$} & \multirow{2}{*}{ Valid } & $\mathrm{b}(2)$ & $\mathrm{b}(3)$ & $\mathrm{b}(2)$ & $\mathrm{b}(2)$ & $\mathrm{b}(2)$ & $\mathrm{b}(2)$ & $\mathrm{b}(\mathrm{I})$ & b (7) & b (4) & $\mathrm{b}(2)$ & b (5) & b (4) \\
\hline & & $d(8)$ & $\mathrm{d}(5)$ & $\mathrm{d}(8)$ & $d(7)$ & $d(8)$ & $d(8)$ & $\mathrm{d}(8)$ & $\mathrm{d}(3)$ & $d(6)$ & $d(7)$ & $d(5)$ & $d(5)$ \\
\hline & \multirow{2}{*}{ Rejected } & e (I) & e (7) & e (3) & e (5) & e (I) & e (I) & e (3) & e (4) & e (4) & e (6) & e (5) & e (6) \\
\hline & & & & $f(I)$ & $f(I)$ & & & $f(3)$ & & & & & \\
\hline
\end{tabular}

MRC - Average value of the shear resistance; $\sigma$-Standard deviation; *b-Rupture of one of the specimen elements in a border of the lap joint; $d$ - Rupture of one of the specimen elements outside the lap joint; e-Rupture near the grip of the stress-measuring device; $\mathrm{f}$-Slippage in the grips of the stress-measuring device

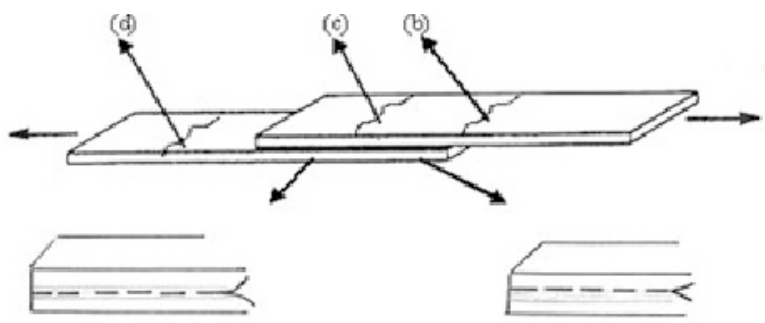

(a1)

(a)

Fig. 7: Failure modes of joints during the shear tests

The standards advocate a series of five specimens. The results of an individual test must be rejected when the specimen breaks inside the grip or less from $10 \mathrm{~mm}$ from its border, and when the specimen slips more than $2 \mathrm{~mm}$ near the grip; when these situations occur, a new test on a new specimen must be performed until valid results can be obtained for five specimens. Fifteen specimens were cut per test sample in the expectation of obtaining at least 10 valid results, which was not always achieved (Table 3). The number of specimens was increased with a view to improving the statistical validation of the calculated results.

\section{Tests Results}

\section{Shear Resistance Test}

The values of the shear resistance (maximum force), the respective strain, and the mode of failure of the joint were recorded for each specimen. The strain is derived from the displacement assuming that only small perturbations occurred.

The failure modes of the specimens are identified in Table 3. Joints ceased functioning as a result of one of the following occurrences (Fig. 7):

- Separation of the two elements of the specimen due to loss of adherence at the welded surface (a1) or

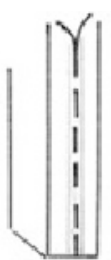

(a1)

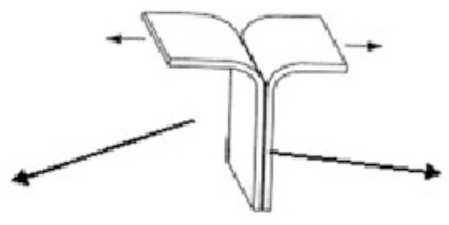

(a)
Fig. 8: Failure modes during the peeling tests

separation of the bituminous layer of the membrane close to the reinforcement of one of the elements (a2);

- Rupture of one of the elements of the specimen at one of the borders of the lap joint (b);

- Rupture of one of the elements of the specimen at the lap joint and consequent separation (c);

- Rupture of one of the elements of the specimen outside the lap joint $(\mathrm{d})$.

The average values of the shear resistance (MRC) and the standard deviation $(\sigma)$ were calculated for each series of valid specimens, and the minimum and maximum strain values corresponding to the maximum force (Table 3) were selected.

In most test specimens, a very small deformation occurred from the moment the maximum force was applied until separation of the two specimen elements occurred, due to adherence loss or until of one of them broke.

\section{Peel Resistance Test}

The tension force and the corresponding strain were continuously recorded for each specimen until the elements came apart. The average value of the peel resistance was determined and the mode of failure of the joint was recorded; the mode of failure (Fig. 8) occurred either by separation of the two elements of the specimen due to loss of adherence at the welded surface (a1) or by separation of the bituminous layer close to the reinforcement of one of the elements (a2).+ 
Table 4-Results of the peel resistance tests (adapted from Gonçalves ${ }^{4}$ )

\begin{tabular}{|c|c|c|c|c|c|c|c|c|c|c|c|c|c|}
\hline \multicolumn{2}{|c|}{ WEATHERING STATE } & \multicolumn{4}{|c|}{ NEW } & \multicolumn{4}{|c|}{ WATER WEATHERED } & \multicolumn{4}{|c|}{ HEAT WEATHERED } \\
\hline \multirow[t]{2}{*}{ LAP JOINTS } & \multirow{2}{*}{$\begin{array}{l}\text { WELDING PROCESS } \\
\text { WIDTH (MM) }\end{array}$} & \multicolumn{2}{|c|}{ GAS TORCH } & \multicolumn{2}{|c|}{ HOT AIR } & \multicolumn{2}{|c|}{ GAS TORCH } & \multicolumn{2}{|c|}{ HOT AIR } & \multicolumn{2}{|c|}{ GAS TORCH } & \multicolumn{2}{|c|}{ HOT AIR } \\
\hline & & 100 & 50 & 100 & 50 & 100 & 50 & 100 & 50 & 100 & 50 & 100 & 50 \\
\hline \multicolumn{2}{|c|}{$\mathrm{MR}_{\max } \mathrm{P}(\mathrm{N})$} & 144 & $|3|$ & 224 & 227 & 222 & 172 & 306 & 257 & 139 & 105 & 149 & 130 \\
\hline \multicolumn{2}{|c|}{$\sigma(\mathrm{N})$} & 28 & 21 & 21 & 37 & 44 & 28 & 26 & 21 & 21 & 14 & 36 & 28 \\
\hline \multirow{2}{*}{ Strain at maximum force (\%) } & Minimum value & 46 & 40 & 48 & 73 & 43 & 37 & 58 & 84 & 32 & 25 & 23 & 44 \\
\hline & Maximum value & 231 & 115 & 267 & 138 & 145 & 131 & 272 & 146 & 115 & 88 & 115 & 106 \\
\hline \multicolumn{2}{|c|}{$\mathrm{MR}_{\text {med }} \mathrm{P}(\mathrm{N})$} & 105 & 108 & 168 & 175 & 196 & 157 & 227 & 204 & 82 & 81 & 98 & 86 \\
\hline \multicolumn{2}{|c|}{$\sigma(\mathrm{N})$} & 15 & 14 & 25 & 46 & 24 & 21 & 32 & 31 & 14 & 17 & 25 & 31 \\
\hline \multirow{3}{*}{$\begin{array}{l}\text { Mode of failure* (number of } \\
\text { specimens tested) }\end{array}$} & \multirow{2}{*}{ Valid } & $a_{l}(10)$ & $a_{I}(10)$ & $a_{1}(10)$ & $a_{1}(10)$ & $a_{1}(10)$ & $a_{I}(10)$ & \multirow{2}{*}{\multicolumn{2}{|c|}{$\begin{array}{l}a_{1}(7) \quad a_{1}(10) \\
a_{3}(3)\end{array}$}} & $a_{1}(3)$ & $a_{1}(3)$ & $a_{\mid}(4)$ & $a_{1}(3)$ \\
\hline & & & & & & & & & & $a_{3}(7)$ & $\mathrm{a}_{3}(7)$ & $a_{3}(6)$ & $a_{3}(7)$ \\
\hline & Rejected & & & $g(4)$ & $g(I)$ & $g(2)$ & & & $g(4)$ & $g(I)$ & $g(I)$ & $g(I)$ & \\
\hline
\end{tabular}

The average value of the maximum peel resistance $\left(\mathrm{MR}_{\max } \mathrm{P}\right)$, the average value of the medium peel resistance $\left(\mathrm{MR}_{\text {med }} \mathrm{P}\right)$, and the corresponding standard deviations were recorded for each series of valid specimens. The minimum and maximum values of the strain corresponding to the maximum force recorded (Table 4) were selected.

\section{ANALYSIS AND DISCUSSION OF THE RESULTS}

\section{Shear Resistance Test}

The performance of the new SBS-modified bituminous membrane lap joints was identical in all the test specimens in relation to the average shear resistance and the failure mode, showing that the lap joints' width and their execution process had little influence.

This conclusion holds for the specimens weathered both by water and heat. The average shear resistance of the lap joints after each of the weathering processes hardly varies with the welding process or the joints' width. The mode of failure is equally similar because, regardless of the welding process, rupture always occurred in one of the specimen's elements, near or outside the joint, and never because of loss of adhesion between them.

However, the results obtained indicate a better performance of the joints after weathering, because the average shear resistance increases with water and even more with heat. But as currently happens, there was a loss of stretching capacity of the material (strain at maximum force) subjected to heat.

For these SBS membranes, whatever the lap joints' width and the welding process (gas torch or hot air), average values of at least $400 \mathrm{~N}$ are expected for the shear resistance.

Figure 9 shows the average values of the shear resistance obtained in the 12 series of tests.

\section{Peel Resistance Test}

The peel performance of the SBS-modified bituminous membrane lap joints, whether new or water or heat weathered, showed some influence of the execution process, and proved to be better for the lap joints made with hot air.

The reduction of the lap joints' width from 100 to $50 \mathrm{~mm}$ did not lead to a significant change in the average value of the peel resistance for the new specimens. However, for the water weathered ones, a decrease of 20 and $10 \%$ was recorded for joints made with a gas torch and hot air, respectively, and for those heat weathered, only those lap joints made with hot air showed a noticeable decrease $(12 \%)$.

Using the results obtained in the tests made with new specimens as a reference, the average values of the maximum and medium peel resistance increased with water weathering and decreased with heat weathering, regardless of the welding process and the lap joint width. Therefore, the well-known sensitivity of this type of membrane to heat was also clear in the peel resistance test. Water apparently does not have a deleterious effect on the performance of lap joints.

Figures 10 and 11 show the average maximum and medium peel resistance in the series of SBS-modified bituminous specimens whose lap joints were made with a gas torch (Fig. 10) and hot air (Fig. 11).

Separation of the two elements of the specimen due to total loss of adherence of the welding occurred in $100 \%$ of the cases for new specimens, for both welding processes.

In the weathered specimens, this failure mode happened in 100 and $70 \%$ of the cases for water weathering, and 70 and $40 \%$ for heat weathering, in lap joints made with gas torch and hot air, respectively. In all the remaining cases, separation of the elements occurred partly in the welding and partly in the bituminous layer next to the reinforcement of one of them. It can then be concluded that heat weathering 


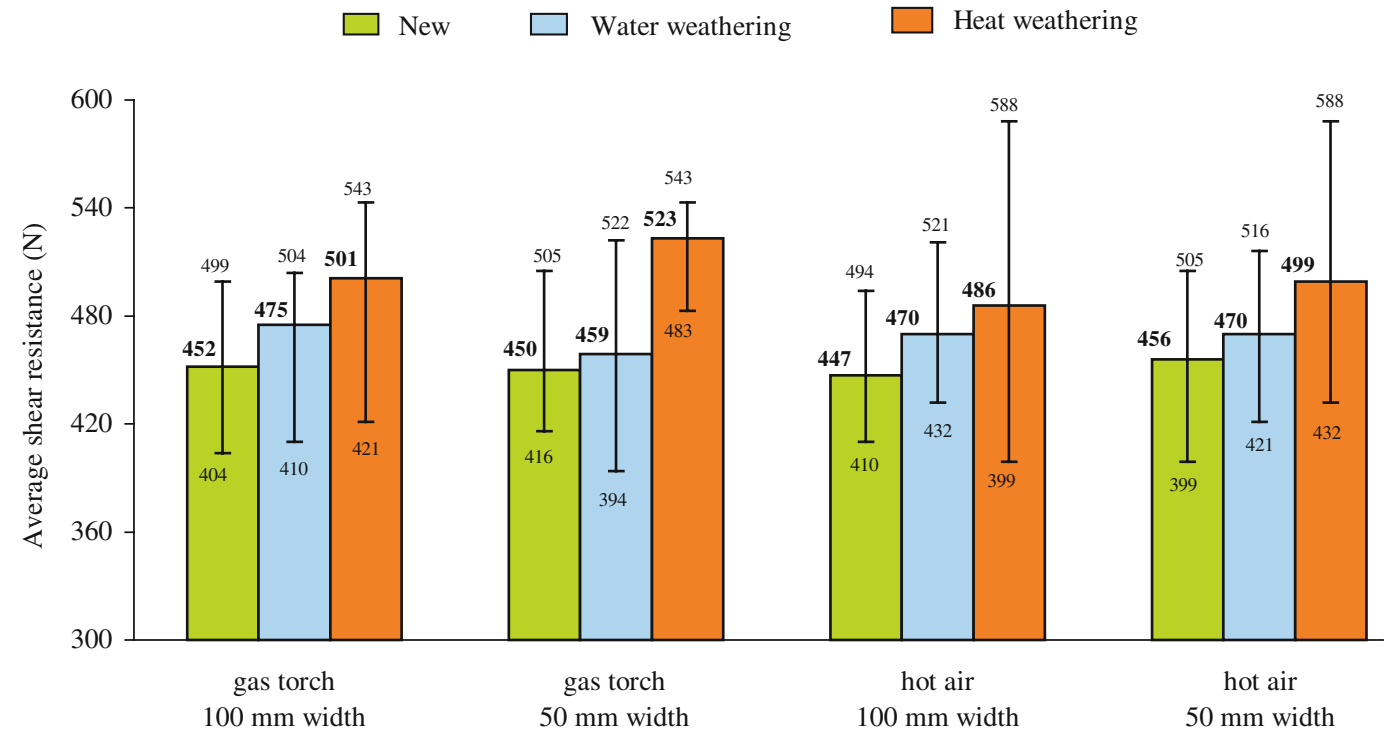

Fig. 9: Average shear resistance of lap joints of SBS-modified bituminous membrane specimens ${ }^{4}$

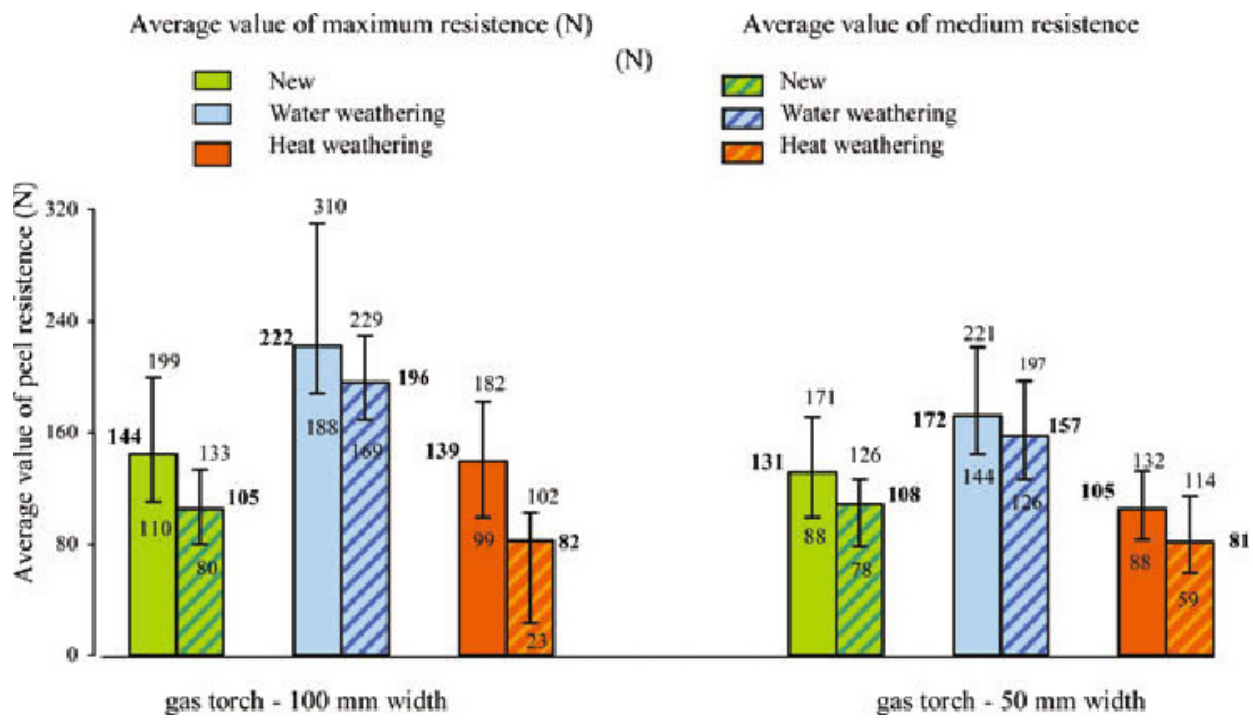

Fig. 10: Average maximum and medium peel resistance of lap joints of SBS-modified bituminous membrane made with gas torch ${ }^{4}$

seems to improve the adherence of the membranes at the lap joint.

\section{ANALYSIS OF CONFORMITY COMPLIANCE OF THE MEMBRANES LAP JOINTS}

Because harmonized European Standards do not establish criteria for the performance of bituminous and synthetic membranes lap joints (in terms of minimum values for a specific application), these data were gathered from the pertinent UEAtc guides, taking into consideration that the main parameters obtained using the test techniques prescribed in those guides are equal to those indicated by the European Standards used in the present experimental campaign.

The 1991 UEAtc guide for single-layer waterproofing systems ${ }^{8}$ establishes requirements for the performance of 
Average value of maximum res istance $(\mathrm{N})$

$\square$ New
$\square$ Water weathering
$\square$ Heat weathering
Average value of medium resistance $(\mathrm{N})$

Da New

Water weathering

Heat weathering

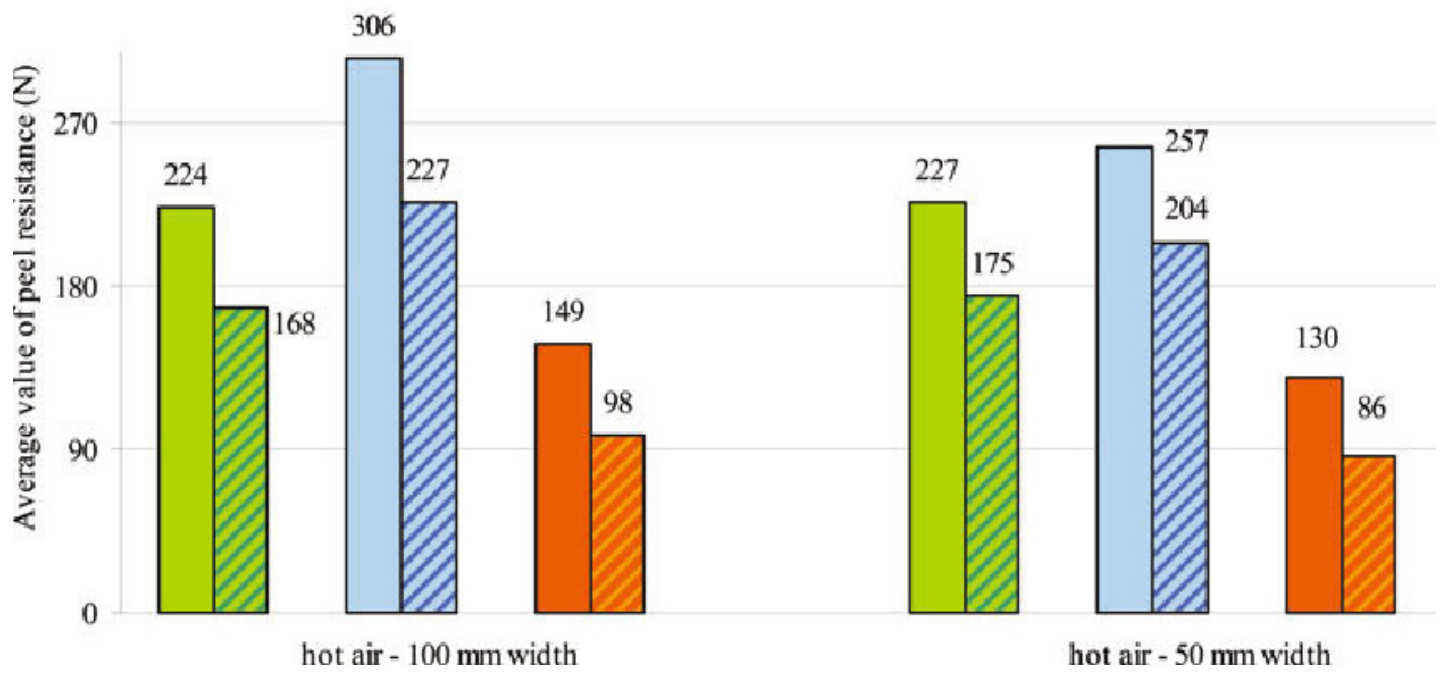

Fig. I I: Average maximum and medium peel resistance of lap joints of SBS-modified bituminous membrane made with hot hair ${ }^{4}$

lap joints in SBS-modified bituminous membranes subjected to shear and peel resistance tests. The performance of lap joints made with a gas welding torch or hot air tested new at a temperature of $+23^{\circ} \mathrm{C}$ complies with the requirements if: In the shear resistance test on new specimens, rupture occurs outside the lap joint or, when otherwise, the specimen presents a minimum shear resistance of $100 \mathrm{~N} / 10 \mathrm{~mm}$; in the peel resistance test, the specimen shows an average peel resistance of at least $10 \mathrm{~N} / 10$ or $15 \mathrm{~N} / 10 \mathrm{~mm}$ for new lap joints and heat weathered lap joints, respectively (for specimens $50-\mathrm{mm}$ wide, the figures would be 500,50 , and 75 $\mathrm{N}$, respectively).

In this UEAtc guide, ${ }^{8}$ the stated requirements (in N/10 mm) are based on the results of tests conducted on $250-\mathrm{mm}$ wide specimens. In this work, tests were carried out on 50 -mm wide specimens, in accordance with the most recent European Standards. ${ }^{9,10}$ Nevertheless, it is reasonable to assume, for the width range in question, a linear variation of the characteristics under analysis.

In a more recent UEATc guide on waterproofing systems made of APP- and SBS-modified bituminous membranes, ${ }^{9}$ criteria are defined for the performance of these membranes' water weathered lap joints.

According to this guide, the performance of new SBS-modified bituminous membranes lap joints is in compliance when, in the shear resistance test, rupture occurs outside the lap joint or, when otherwise, the specimen presents a minimum shear resistance of $500 \mathrm{~N} / 50 \mathrm{~mm}$ (as in the older UEATc guide $^{8}$ ); in the peel resistance test, the specimen must show an average peel resistance of at least $100 \mathrm{~N} / 50 \mathrm{~mm}$ (twice the one prescribed in the older UEATc guide ${ }^{8}$ ). It must be noted that the requirements for the shear resistance defined in Ref. 9 only apply to lap joints made with special bituminous glues, which is not the present case. However, because the criterion is the same as in Ref. 8, its compliance will be verified.

Furthermore, the new guide ${ }^{9}$ states that after water weathering the variation of the shear and peel resistance (relative to the one for new specimens) should not exceed $20 \%$. In every case, this demand is satisfied.

The results for the valid specimens of each test sample whose performance complied with the demands indicated in UEAtc guides mentioned ${ }^{8,9}$ are quantified in Table 5.

\section{FINAL REMARKS}

The shear resistance of SBS-modified bituminous specimens' lap joints, which were found not to be influenced either by the lap joint width or by the execution process, slightly increases with water weathering and decreases with heat weathering.

The peel resistance of SBS-modified bituminous specimens' lap joints shows a very significant increase with water weathering and a reasonable decrease with heat weathering, regardless of the welding process and lap joint width.

However, peel resistance is higher for lap joints made with hot air than it is for those made by gas torch. Furthermore, peel resistance decreases with the lap joint width in 
Table 5-Analysis of the conformity of the SBS-modified bituminous membrane lap joints tested (adapted from Gonçalves ${ }^{4}$ )

\begin{tabular}{|c|c|c|c|c|c|c|}
\hline \multirow[b]{2}{*}{$\begin{array}{l}\text { WEATHERING } \\
\text { STATE }\end{array}$} & \multirow[b]{2}{*}{$\begin{array}{l}\text { WELDING } \\
\text { PROCESS }\end{array}$} & \multirow[b]{2}{*}{$\begin{array}{c}\text { LAP JOINT } \\
\text { WIDTH (MM) }\end{array}$} & \multicolumn{2}{|c|}{ SHEAR RESISTANCE TEST } & \multicolumn{2}{|c|}{ PEEL RESISTANCE TEST } \\
\hline & & & $\begin{array}{l}\text { NUMBER OF VALID } \\
\text { SPECIMENS } \\
\text { TESTED }\end{array}$ & $\begin{array}{l}\text { NUMBER OF SPECIMENS } \\
\text { WITH COMPLIANT } \\
\text { PERFORMANCE (I) }\end{array}$ & $\begin{array}{l}\text { NUMBER OF VALID } \\
\text { SPECIMENS TESTED }\end{array}$ & $\begin{array}{c}\text { NUMBER OF } \\
\text { SPECIMENS WITH } \\
\text { COMPLIANT } \\
\text { PERFORMANCE (2) }\end{array}$ \\
\hline \multirow{4}{*}{ New } & \multirow[b]{2}{*}{ Gas torch } & 100 & 10 & 10 & 10 & $9 *[8]$ \\
\hline & & 50 & 8 & 8 & 10 & $\begin{array}{c}5[9] \\
10[8] \\
8[9]\end{array}$ \\
\hline & \multirow{2}{*}{ Hot air } & 100 & 10 & 10 & 10 & $10[8]$ and [9] \\
\hline & & 50 & 9 & 9 & 10 & $10[8]$ and [9] \\
\hline \multirow{4}{*}{ Heat weathered } & \multirow{2}{*}{ Gas torch } & 100 & 10 & (3) & 10 & 7 \\
\hline & & 50 & 9 & (3) & 10 & 6 \\
\hline & \multirow{2}{*}{ Hot air } & 100 & 10 & (3) & 10 & 9 \\
\hline & & 50 & 9 & (3) & 10 & 10 \\
\hline \multirow{4}{*}{ Water weathered } & \multirow{2}{*}{ Gas torch } & 100 & 10 & 10 & 10 & 10 \\
\hline & & 50 & 10 & 10 & 10 & 10 \\
\hline & \multirow{2}{*}{ Hot air } & 100 & 9 & 9 & 10 & 10 \\
\hline & & 50 & 10 & 10 & 10 & 10 \\
\hline
\end{tabular}

(1) UEAtc guides ${ }^{8,9}$ define the same requisite for the shear resistance test in new specimens. (2) UEAtc guides, define different requisite for the peel resistance test in new specimens. (3) UEAtc guide ${ }^{8}$ does not define any requisite for the shear behavior of lap joints heat weathered. * An undetected failure of the stress-measuring device eliminated the continuous recording of the force rendering impossible the determination of the average resistance in one of the 10 tests.

those specimens made by gas torch and water weathered, and in those made by hot air with both types of weathering.

In general, SBS-modified bituminous membranes proved adequate in single-layer systems according to the requisites defined in the applicable UEATc guides. A satisfactory performance of these membranes in mechanically fastened systems is thus expected, and their resistance should be evaluated using the well-known wind suction tests prescribed in corresponding EOTA guide. ${ }^{6}$

\section{References}

1. Rossiter, W.J., "Tests of Adhesive-Bonded Seams of SinglePly Rubber Membranes," Symposium Roofing Research and Standards Development, New Orleans, LA; December 3, 1986.

2. Oba, K., "Flats Roofs: investigation of Heat Welding Techniques for Polymer-Modified Bituminous Roofing Membranes," Dissertation, Kungliga Tekniska Hogskolan, Stockholm (1994).

3. Walter, A., de Brito, J., and Lopes, J.G., "Current Flat Roof Bituminous Membranes Waterproofing Systems-Inspection, Diagnosis and Pathology Classification," Construction Building Materials 19:233-242 (2005).
4. Gonçalves, M., "Flat Roofs Waterproofing Systems Based on Prefabricated Membranes. Lap Joints Performance," (in Portuguese) Masters in Construction Dissertation, IST, Technical University of Lisbon, Lisbon (2004).

5. Gonçalves, M., Lopes, J.G., de Brito, J., and Lopes, A.G., "Mechanical Performance of Lap Joints of Flat Roof Waterproofing Membranes," Experimental Techniques, 32:50-57 (2008).

6. ETAG 006, "Guideline for European Technical Approval of Systems of Mechanically Fastened Flexible Roof Waterproofing Membranes," EOTA, March (2000).

7. EN 13707, "Flexible Sheets for Waterproofing. Reinforced Bitumen Sheets for Roof Waterproofing. Definitions and Characteristics," CEN, Brussels (2005).

8. UEAtc, "UEAtc Special Technical Guide for the Assessment of Single Layer Roof Waterproofing," UEAtc, Paris, June (1991).

9. UEAtc, "UEAtc Technical Guide for the Assessment of Roof Waterproofing Systems Made of Reinforced APP or SBS Polymer Modified Bitumen Sheets," UEAtc, Paris, December (2001).

10. Cahier No. 1812 du CSTB, "Directives générales UEAtc pour l' agrément des revêtements d' étanchéité de toitures," UEAtc, Paris, July (1982).

11. EN 12317-1, "Flexible Sheets for Waterproofing. Part 1: Bitumen Sheets for Roof Waterproofing. Determination of Shear Resistance of Joints," CEN, Brussels (2001).

12. EN 12316-1, "Flexible Sheets for Waterproofing. Part 1: Bitumen Sheets for Roof Waterproofing. Determination of Peel Resistance of Joints," CEN, Brussels (2001). 